Research Article

\title{
Nutrient Release Pattern and Greenhouse-Grown Swiss Chard Response to Biochar Inoculated with Vermicast
}

\author{
Lord Abbey $\mathbb{D}^{1},{ }^{1}$ Jinsheng Cai $\mathbb{D}^{1},{ }^{1}$ Lokanadha $R$. Gunupuru $\mathbb{D},{ }^{1}$ Mercy Ijenyo $\mathbb{D},{ }^{1}$ \\ Ebenezer O. Esan $\mathbb{D}^{2}{ }^{2}$ and Suwen Lin $\mathbb{D}^{1}$ \\ ${ }^{1}$ Department of Plant, Food, and Environmental Sciences, Dalhousie University, Faculty of Agriculture, 50 Pictou Road, \\ P.O. Box 550, Truro B2N 5E3, Nova Scotia, Canada \\ ${ }^{2}$ The University of Western Ontario, Department of Biology, 1151 Richmond Street, London N6A 3K7, ON, Canada
}

Correspondence should be addressed to Lord Abbey; loab07@gmail.com

Received 7 March 2020; Accepted 27 March 2020; Published 14 April 2020

Academic Editor: Maria Serrano

Copyright (c) 2020 Lord Abbey et al. This is an open access article distributed under the Creative Commons Attribution License, which permits unrestricted use, distribution, and reproduction in any medium, provided the original work is properly cited.

A study was performed to assess nutrient release from biochar inoculated with solid vermicast (SVB), vermicast tea (VTB), deionized water (DWB), uninoculated biochar (Bioc), and Promix-BX (Pro-BX). The growth response of Swiss chard (Beta vulgaris subsp. vulgaris) cv. Rhubarb chard was also assessed. Comparatively, nutrients were released slowly from treatments SVB and VTB compared to the other treatments. The rate of nutrient release determined by total dissolved solids and electric conductivity from the Pro-BX was the highest. The trend for the plant growth components, total leaf surface area and leaf fresh weight at first harvest, was Pro-BX $>$ Bioc $>$ DWB $=\mathrm{SVB}>\mathrm{VTB}$. The only treatment that increased total leaf area and leaf fresh weight at the second harvest by approximately 1.02 - and 1.88 -fold was VTB. Leaf fresh weight was significantly reduced by approximately 0.33 -fold for DWB, 0.28 -fold for Bioc, and 0.70-fold for Pro-BX but was not altered by SVB at the second harvest as compared to the first harvest. A 2-dimensional principal component analysis (PCA) biplot confirmed that treatment Pro-BX increased plant growth components at the first harvest only. The locations of SVB and VTB on the PCA biplot confirmed their efficacies, which led to increases in the plant growth components at the second harvest. Overall, the VTB adsorbed more nutrients onto its surface that were slowly released to enhance the Swiss chard cv. Rhubarb chard plant growth at the second harvest. Further studies should consider microbial activities.

\section{Introduction}

Globally, more research is being focused on climate-smart agricultural technologies and sustainable food production in order to meet the current and future food and dietary demands [1-3]. As such, most farmers adopt intensive use of synthetic chemical fertilizers, which can be detrimental to the environment, ecological system, and the health of life forms. The use of organic amendments such as vermicast and biochar for both field and controlled-environment production is professed as sustainable clean technology.

Grewal et al. [4] reviewed that biochar is obtained from thermochemical conversion of biomass in an oxygen-limited environment by the process of pyrolysis. Many studies have shown that biochar can enhance the biological, physical, and chemical properties of growing media. These include improvements in soil structure, slow release of nutrients, sequestration of carbon, cation exchange capacity, sorption capacity, water-holding capacity, and soil fertility $[5,6]$. However, it is worth noting that the nature and type of biomass and the method of the pyrolytic process such as temperature used can influence the physical and chemical properties of the biochar and its efficacy. These properties of biochar have drawn the attention of many researchers, environmentalists, and farmers leading to increased use in the environmental and agricultural sectors worldwide. Essentially, the benefit of biochar is dependent on the rate of biochar application, the properties of the growing medium, and the genotypic characteristics of the plant [7]. Biochar ability to support plant growth is determined by the 
surrounding growing medium chemistry that it interacts with. According to Rees et al. [7], the chemical status of soil can influence the efficacy of biochar.

Inoculation of biochar using organic amendment or synthetic chemical fertilizer triggers its adsorptive surface with abundant nutrients in addition to the creation of optimal microenvironment for microbial growth and increased water storage capacity [7-10]. Ultimately, the functionality of the growing medium is enhanced. However, the previous study showed that, by virtue of the high $\mathrm{pH}$, biochar can immobilize major nutrients such as calcium, nitrate-nitrogen, and phosphorus [7]. This can be a major problem when using biochar since these nutrients may become unavailable to plants. Also, such immobilization activity can influence the pattern of nutrient release to plants. Furthermore, the activities of microbial communities as well as other physical characteristics such as water availability and the structure of the growing medium can also influence the release and availability of nutrients to plants. It is therefore hypothesized that intentional inoculation of biochar can circumvent these potential problems related to nutrient release and plant uptake. Materials that can be used to inoculate biochar include vermicast, thermophilic compost, biosolids, animal manure, and liquid fertilizer [3]. Despite this knowledge, the pattern of nutrient release from inoculated biochar using natural amendments such as vermicast with respect to time of application is not well understood. This is the main thrust of the current study.

Vermicast is rich in microorganisms and plant growthpromoting chemical compounds derived from humic and nonhumic substances, which include mineral nutrients, organic acids, nucleic acids, macromolecules, and antimicrobial and pesticidal compounds [11]. It is therefore expected that the characteristic effect of vermicast-inoculated biochar will be significantly higher than if it was not inoculated, as explained by Beesley et al. [9]. And although the nutrient release rate of the inoculated biochar is expected to be low, it is hypothesized that the synergetic benefits derived from the combination of biochar and vermicast through inoculation and incubation procedures will be highly efficacious. The effect of residual nutrients from inoculated biochar on plant growth also needs to be investigated. Therefore, the objective of the study was to assess and compare the nutrient release pattern of solid vermicastinoculated biochar, vermicast tea-inoculated biochar, and biochar alone and their residual effects on plant growth. The test plant was Swiss chard (Beta vulgaris subsp. vulgaris cv. Rhubarb chard), which was chosen for its ease of production during the cool weather in fall and winter, and its ability to withstand sequential harvesting required for the assessment of plant response to growing medium nutrient residue.

\section{Materials and Methods}

2.1. Location and Materials. The study was carried out in the Compost and Biostimulant Laboratory and the research greenhouse located in the Department of Plant, Food, and Environmental Sciences, Dalhousie University, Faculty of Agriculture, from April to December 2017. The biochar from white pine (Pinus strobus) was produced through pyrolysis at $11,000^{\circ} \mathrm{C}$ and was obtained from Proton Power Inc., TN, USA; vermicast from red wiggler (Eisenia fetida) was purchased from Co-op Country Store, Truro, NS, Canada; Promix-BX ${ }^{\mathrm{TM}}$ (Premier Horticulture Inc., Quakertown, USA); a general-purpose peat-based substrate consisted of $75 \%-85 \%$ sphagnum peat moss, horticultural-grade perlite and vermiculite, chemical fertilizer, dolomitic and calcitic limestone, a wetting agent, and mycorrhizal fungus (Glomus intraradices) was purchased from Halifax Seed Inc., Halifax, NS, Canada. Seeds of Swiss chard (Beta vulgaris subsp. vulgaris cv. Rhubarb chard) was also purchased from Halifax Seed Inc.

2.2. Biochar Inoculation and Chemical Analysis. The biochar was inoculated with solid vermicast at $45 \%$ moisture content, vermicast tea, and distilled water alone for 40 days. The vermicast tea was made by adding a liter of distilled water to $100 \mathrm{~g}$ of solid vermicast and stirred at $1200 \mathrm{rpm}$ for $24 \mathrm{hr}$ using DLM1886X1 Isotemp stirring plate (Fisher Scientific Inc., Markham, ON, Canada). The biochar was then inoculated with the vermicast tea (VTB) by thoroughly mixing $500 \mathrm{~g}$ of solid dry biochar and one liter of the vermicast tea prior to incubation. The solid vermicast-inoculated biochar (SVB) was made by thoroughly mixing $500 \mathrm{~g}$ of the solid dry biochar and $100 \mathrm{~g}$ of the solid vermicast prior to incubation. The deionized water-inoculated biochar (DWB) was made by thoroughly mixing $500 \mathrm{~g}$ of the dry biochar and one liter of deionized water prior to incubation. The individual mixtures were then incubated for 40 days in the dark at room temperature $\left(c a .21^{\circ} \mathrm{C}\right)$ and relative humidity conditions. The control treatments were $500 \mathrm{~g}$ of the dry biochar alone and $500 \mathrm{~g}$ of Promix-BX potting mix alone also incubated under the same room conditions. All the treatments were in triplicate. Samples $(100 \mathrm{~g})$ of each of the growing medium substrates were sent to the Nova Scotia Department of Agriculture (NSDA) Laboratory Services, Truro, NS, for nutrient analysis. Total nitrogen $(\mathrm{N})$ was determined by the AOAC-990.03 combustion method [12] using a LECO-Spec Analyzer (TruSpec ${ }^{\circledR}$ Micro, LECO, MI), while calcium (Ca), potassium $(\mathrm{K})$, phosphorus $(\mathrm{P})$, magnesium $(\mathrm{Mg})$, sodium $(\mathrm{Na})$, boron $(\mathrm{B})$, copper $(\mathrm{Cu})$, iron $(\mathrm{Fe})$, manganese $(\mathrm{Mn})$, and zinc $(\mathrm{Zn})$ were determined using the AOAC-968.08 inductively coupled plasma (ICP) spectrometer method [13].

2.3. Nutrient Release and Electrochemical Analysis. A nutrient release study was performed in the laboratory using a cylindrical glass jar measuring $35 \mathrm{~cm}$ in height and $10 \mathrm{~cm}$ for the inner diameter. Each glass jar was filled with one liter of deionized water, and the dissolved matter and released nutrients in solution were determined using the method described by Abbey et al. [14] with slight modification. In brief, $20 \mathrm{~g}$ of each of the five growing medium treatments was placed separately in a HEPA filter grade Rosin Tech nylon press bag (Rosin Tech Products, CA, USA) with a mesh size of $25 \mu \mathrm{m}$ and a dimension of $6.35 \mathrm{~cm} \times 10.16 \mathrm{~cm}$. The individual samples were submerged in the deionized water in the glass jar. $20 \mathrm{ml}$ samples of the solution from the 
individual glass jars were collected with replacement every $10 \mathrm{~min}$ for $1 \mathrm{hr}$, every $30 \mathrm{~min}$ for $2 \mathrm{hr}$, every $1 \mathrm{hr}$ for $5 \mathrm{hr}$, every $2 \mathrm{hr}$ for $6 \mathrm{hr}$, every $5 \mathrm{hr}$ for $10 \mathrm{hr}$, and every $24 \mathrm{hr}$ for 24 days. Oakton PC Tester 35 multimeter (Oakton Instruments, IL, USA) was then used to record the $\mathrm{pH}$, total dissolved solids, electric conductivity, and salinity of the solutions collected before pouring them back into the glass jar. LAQUA Twin ion meter (HORIBA, Minami-ku, Kyoto, Japan) was also used to measure calcium $\left(\mathrm{Ca}^{2+}\right)$, nitrate $\left(\mathrm{NO}^{-3}\right)$, sodium $\left(\mathrm{Na}^{+}\right)$, and potassium $\left(\mathrm{K}^{+}\right)$ion concentrations of each collected sample per treatment.

2.4. Greenhouse Experiment. A pot experiment was performed in the department's greenhouse at an average temperature of $28^{\circ} \mathrm{C} / 16^{\circ} \mathrm{C}$ (day/night cycle) and relative humidity of $76 \%$. Supplemental lighting was provided by a 600 W HS2000 high-pressure sodium lamps with NAH600.579 ballast (P.L. Light Systems, Beamsville, ON, Canada) at $12 \mathrm{hr}$ light cycle between November and December when days got shorter or on cloudy days. Plastic pots $(15.24 \mathrm{~cm}$ diameter) were filled to the same volume of a mixture of the individual components as shown in Table 1. The variation in weight was due to the differences in bulk density (data not presented). The weight of the uninoculated dry biochar prior to inoculation was $200 \mathrm{~g}$. Each treatment had four potted plants placed in saucers per replication, and they were replicated four times to give a total of $80 \mathrm{ex}$ perimental units. Each pot was planted with one seedling of Swiss chard and watered with approximately $200 \mathrm{ml}$ of tap water (based on previous work) every two to three days depending on the weather conditions. By this method, nutrient loss through leachate was avoided.

2.5. Plant Growth Analysis. Plant height was measured from the stem collar to the tip of the longest leaf using a $30 \mathrm{~cm}$ ruler at first harvest, which was four weeks after transplanting. The other growth measurements were stem diameter, which was measured from the middle portion of the stem using a pair of Mastercraft calipers (Canadian Tire. Toronto, ON, Canada); total plant fresh weight was recorded prior to total dry weight determination by drying the samples in an 52100-10 Cole-Parmer mechanical convection oven dryer (Cole-Parmer Instrumental Company, Vernon Hills, Ill., USA) at $65^{\circ} \mathrm{C}$ for $24 \mathrm{hr}$; plant mass density was determined from the dry weights according to the method of Louw-Gaume et al. [15]. The number of edible leaves per treatment was also recorded at first harvest. The two youngest leaves on each plant were left for the plants to regrow for a second harvest at eight weeks after transplanting. The weights of the harvested leaves were recorded using an electronic MXX-412 Denver precision balance (Denver Instrument Company, CO, USA). The total leaf area was determined using a LI-3100 Leaf Area Meter (Li-Cor Inc., Lincoln, NE, USA). Measurements of plant height, stem diameter, and leaf area were performed again at the second harvest (i.e., 8 weeks after transplanting) for comparison with those recorded at the first harvest (i.e., 4 weeks after transplanting).
2.6. Leaf Tissue Pigmentation and Nutrient Analysis. Leaf greenness was used to estimate leaf chlorophyll content using a 502 SPAD meter (Spectrum Technologies Inc., Aurora, Ill., USA). Anthocyanin content was estimated using a portable ACM200+ anthocyanin content meter (OptiSciences, Inc., Hudson, NY, USA). Chlorophyll fluorescence indices were used to determine plant stress level using portable OS30p + Chlorophyll Fluorometer (Opti-Sciences, Inc., Hudson, NY, USA). The Chlorophyll Fluorometer calculated the maximum quantum yield or efficiency of photosystem II as follows:

$$
\frac{\mathrm{Fv}}{\mathrm{Fm}}=\left[\frac{\mathrm{Fm}-\mathrm{Fo}}{\mathrm{Fm}}\right],
$$

where $\mathrm{Fo}$ is the minimum fluorescence, $\mathrm{Fm}$ is the maximum fluorescence, and $\mathrm{Fv}$ is the variable fluorescence indices [16].

The Swiss chard leaf greenness, anthocyanin content, and chlorophyll fluorescence indices were all recorded from the $3^{\text {rd }}$ and $4^{\text {th }}$ leaves of each plant per treatment. Samples of plant leaf tissues were also sent to the NSDA Laboratory Services for nutrient analysis. The leaf samples were washed with distilled water, air-dried, and then packed in paper bags before sending for nutrients analyses. In brief, the plant leaf samples were oven-dried at $60^{\circ} \mathrm{C}$ for $48 \mathrm{hr}$ and ground into powder. Total N, Ca, K, P, Mg, Na, B, Cu, Fe, Mn, and Zn were determined using methods described in $[12,13]$.

2.7. Experimental Design and Statistical Analysis. The experiment was arranged in a complete randomized design with four replications for the greenhouse experiment but three replications for the nutrient release experiment. For the greenhouse pot experiment, each of the five treatments had four samples of plants and a total of 16 potted plants per treatment. Data on leaf greenness and anthocyanin content, plant height, stem diameter, and leaf area were analyzed by one-way analyses of variance (ANOVA) using SAS version 9.4 software (SAS Institute Inc., Cary, NC, USA). Whenever the ANOVA indicated a significant difference, i.e., $P \leq 0.05$, Fisher's protected least significant difference (LSD) at $\alpha=5 \%$ was used to separate the means. Graphs of $\mathrm{pH}$, total dissolved solids, electrical conductivity, salinity, calcium, nitrate, sodium, and potassium were plotted for the nutrient release experiment using Microsoft Excel. A biplot of principal component analysis was performed to determine the association between the growing media treatments and the plant growth components of the Swiss chard cv. Rhubarb chard using XLSTAT version 19.1.

\section{Results and Discussion}

Considerable variations were found in the composition of nutrients in the individual growing medium components, i.e., the solid vermicast-inoculated biochar (SVB), vermicast tea-inoculated biochar (VTB), deionized water-inoculated biochar (DWB), biochar alone (Bioc), and the Promix-BX (Pro-BX) alone (Table 2). The SVB had higher amounts of N, $\mathrm{P}, \mathrm{Na}, \mathrm{B}$, and $\mathrm{Zn}$ as compared to all the other biochar treatments except the VTB treatment, which had 
TABLE 1: Composition of individual vermicast-inoculated biochar treatments.

\begin{tabular}{lccc}
\hline Treatment & Inoculated biochar $(\mathrm{g})$ & Promix-BX added $(\mathrm{g})$ & Total weight of mixture $(\mathrm{g})$ \\
\hline Bioc & 200 & 560 & 760 \\
DWB & 470 & 540 & 1010 \\
SVB & 240 & 520 & 760 \\
VTB & 445 & 490 & 935 \\
Pro-BX & 0 & 800 & 800 \\
\hline
\end{tabular}

comparable amounts of $\mathrm{N}, \mathrm{K}, \mathrm{Mg}$, and $\mathrm{Na}$. However, the manufacturer's premixed medium Promix-BX (Pro-BX) with synthetic chemical fertilizer had the highest amounts of $\mathrm{Ca}, \mathrm{Mg}$, and $\mathrm{Cu}$ and a similar amount of $\mathrm{N}$ as found in the SVB and the VTB. The uninoculated biochar (Bioc) that was used in this study and the DWB had the highest amounts of $\mathrm{Mn}$ and Fe, respectively, but these two treatments contained the least amounts of all the other remaining nutrients.

The richness in nutrients of the two types of vermicastinoculated biochar (i.e., SVB and VTB) compared to the Bioc and the DWB was expected. Cocomposting or combination of biochar and natural amendments was reported to increase biochar nutrient adsorption and overall growing medium fertility status $[9,10,17]$. Typically, vermicast is valued for its richness and diversity in humic and nonhumic substances including macro- and micronutrients and other plant growth factors [11]. These vermicast chemicals can alter the properties of biochar when combined or cocomposted. Based on the reports by Pietikainen et al. [8] and Sizmur et al. [18], we can fairly suggest that the biochar inoculated with the dry solid vermicast (SVB) or the vermicast tea (VTB) became activated with ionized nutrients that enhanced the functionality of the biochar. This assertion will have to be verified in future studies.

The nutrient release experiment showed that initial water activity prior to the dissolution of soluble materials such as surface wetting followed by water imbibition by the particles constituting the mixed media led to a lag phase within the first few hours when they were submerged in the deionized water (Figures 1(a)-1(d)). Consequently, changes in $\mathrm{pH}$, total dissolved solids (TDS), salinity, and electric conductivity (EC) were initially slow before rapidly increasing continuously up to the $100^{\text {th }}$ hour ( $c a .4^{\text {th }}$ day) before slowing down to the end of the experiment on the $495^{\text {th }}$ hour (ca. day 21). The high positive correlation exiting between EC and total nutrient concentration allows for its use to estimate growing medium fertility status [19]. Compared to all the other indices, the trend for the changes in $\mathrm{pH}$ of the solutions for all the treatments was different (Figure 1(a)).

The $\mathrm{pH}$ of the solution rapidly declined within the first 40 min before steeply rising to reach a peak at the $8^{\text {th }}$ hour followed by a steep fall at the $24^{\text {th }}$ hour. Overall, there were no clear differences in salinity, TDS, $\mathrm{pH}$, and EC of the solutions for the SVB, VTB, DWB, and the Bioc apart from the obvious fluctuations in the line graph for treatment DWB. According to Sizmur et al. [18], the manifestation of chemical sorption is attributed to ion exchange and numerous functional groups on the carbonaceous surface of biochar. As such, the fluctuations in the line graphs for the DWB in Figures 1(a)-1(d) can be ascribed to low chemical
TABLE 2: Mineral nutrient composition of the growing media components.

\begin{tabular}{lccccc}
\hline Nutrients & Biochar alone & DWB & SVB & VTB & Pro-BX \\
\hline $\mathrm{N}(\%)$ & 0.570 & 0.540 & 0.640 & 0.610 & 0.630 \\
$\mathrm{Ca}(\%)$ & 1.498 & 1.556 & 1.573 & 1.658 & 2.653 \\
$\mathrm{~K}(\%)$ & 0.039 & 0.042 & 0.049 & 0.050 & 0.033 \\
$\mathrm{P}(\%)$ & 0.066 & 0.055 & 0.091 & 0.082 & 0.065 \\
$\mathrm{Mg}(\%)$ & 0.156 & 0.165 & 0.175 & 0.171 & 0.217 \\
$\mathrm{Na}(\%)$ & 0.037 & 0.037 & 0.052 & 0.051 & 0.028 \\
$\mathrm{~B} \mathrm{(mg/l)}$ & 17.01 & 16.93 & 18.82 & 17.85 & 17.37 \\
$\mathrm{Cu}(\mathrm{mg} / \mathrm{l})$ & 15.90 & 15.30 & 11.99 & 10.95 & 24.62 \\
$\mathrm{Fe}(\mathrm{mg} / \mathrm{l})$ & 550.32 & 1064.92 & 637.32 & 792.61 & 497.14 \\
$\mathrm{Mn}(\mathrm{mg} / \mathrm{l})$ & 501.80 & 452.10 & 437.69 & 346.61 & 87.23 \\
$\mathrm{Zn}(\mathrm{mg} / \mathrm{l})$ & 589.53 & 504.09 & 793.37 & 486.73 & 658.70 \\
\hline
\end{tabular}

$\mathrm{N}$, nitrogen; Ca, calcium; $\mathrm{K}$, potassium; $\mathrm{P}$, phosphorus; $\mathrm{Mg}$, magnesium; $\mathrm{Na}$, sodium; B, boron; $\mathrm{Cu}$, copper; $\mathrm{Fe}$, iron; $\mathrm{Mn}$, manganese; $\mathrm{Zn}$, zinc; DWB, deionized water-inoculated biochar; SVB, solid vermicast-inoculated biochar; VTB, vermicast tea-inoculated biochar; Pro-BX, Promix-BX.

activity in the deionized water as compared to the vermicastinoculated biochar treatments. The values of all the measured water quality indices for the Pro-BX treatment were found to be higher than the respective values for SVB, VTB, DWB, and Bioc treatments. However, the differences began to show after the $300^{\text {th }}$ hour. These findings demonstrated the slow release of nutrients from the biochar treatments compared to the Pro-BX. Particularly, the DWB seemed to be the fastest in releasing its nutrients while the SVB and the Bioc seemed to be intermediate. It was noticed that the release of materials into the solution and the $\mathrm{pH}$ for treatment Pro-BX seemed to be generally more stable after the $350^{\text {th }}$ hour of sampling compared to the other treatments.

The release of nitrate $\left(\mathrm{NO}^{3-}\right)$ into the deionized water from the Pro-BX treatment was the fastest compared to all the biochar treatments and was followed by a steep decline immediately after $2 \mathrm{hr}$ of submergence (Figure 2(a)). After the $150^{\text {th }}$ hour, the amount of $\mathrm{NO}^{3-}$ released into the solution from the Pro-BX did not change. However, $\mathrm{NO}^{3-}$ released into solution from the SVB, DWB, VTB, and the Bioc showed significant fluctuations throughout the sampling period which lasted for $591 \mathrm{hr}$ ( $c a .24 .6$ days). The fluctuations can be attributed to microbial and chemical activities such as bioconversion of $\mathrm{N}$, anion exchange, and volatilization but were not determined in the present study. A lag phase prior to the first $50^{\text {th }}$ hour followed by a rapid increase in ionic concentrations of $\mathrm{K}^{+}, \mathrm{Na}^{+}$, and $\mathrm{Ca}^{+2}$ in the sampled solution (Figures 2(b)-2(d)) was also observed. The concentrations of $\mathrm{K}^{+}$and $\mathrm{Na}^{+}$in the sampled solutions from all the treatments increased exponentially while that of the 


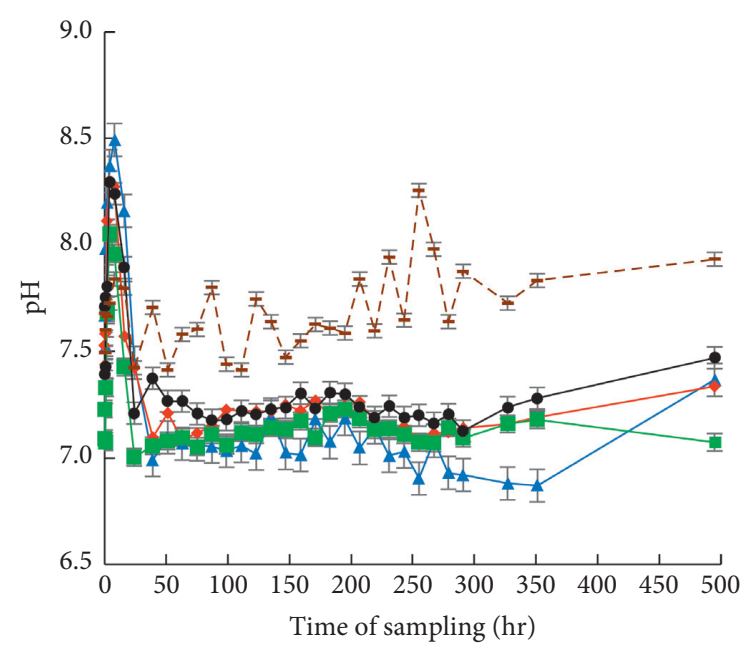

(a)

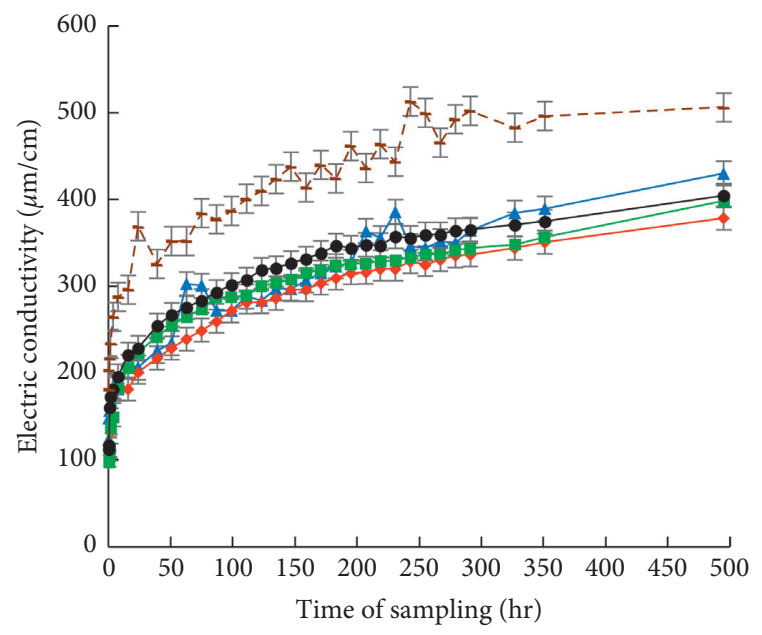

(c)

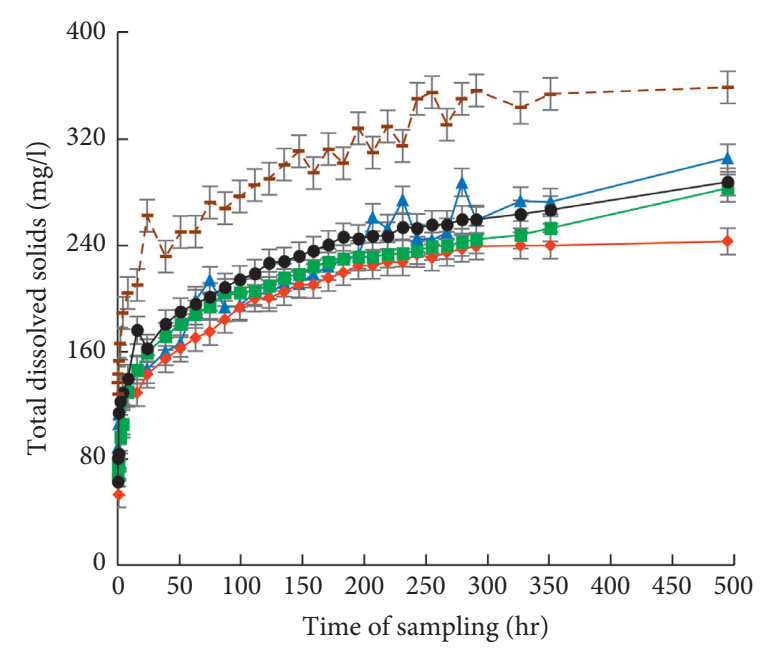

(b)

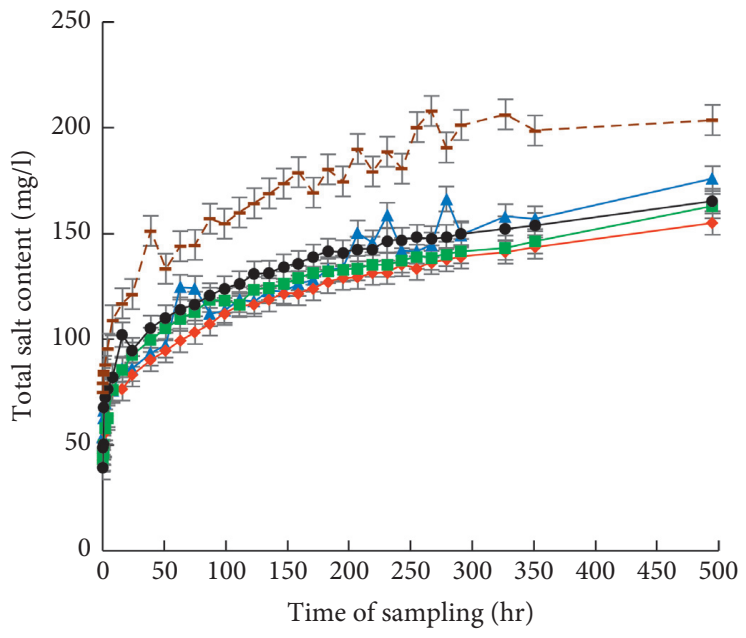

(d)

FIGURE 1: Changes in $\mathrm{pH}$, total dissolved solids, salinity, and electric conductivity of solid vermicast-inoculated biochar (solid line, green square), vermicast tea-inoculated biochar (solid line, red rhombus), deionized water-inoculated biochar (solid line, blue triangle), biochar alone (solid line, black round), and Promix-BX alone (broken line, brown dash) in deionized water. Vertical lines represent standard error bars.

$\mathrm{Ca}^{2+}$ seemed to have increased linearly as sampling time progressed. Amongst the biochar treatments, the highest $\mathrm{K}^{+}$ concentration was recorded by the DWB treatment and the least was recorded by the Bioc treatment, while the SVB and the VTB treatments were in between and not different.

Comparatively, the release of $\mathrm{K}^{+}$and $\mathrm{Na}^{+}$into solution from the Pro-BX was instant and consistently the least just like the $\mathrm{NO}^{3-}$. This can be attributed to the highly soluble nature of $\mathrm{K}$ and $\mathrm{Na}$ salts. However, the release of $\mathrm{Na}^{+}$into solution was not different amongst the four biochar treatments. On the contrary, the release of $\mathrm{Ca}^{2+}$ into solution from the Pro-BX treatment was the fastest and the highest and was represented by a sigmoidal curve in Figure 2(c). The result showed that the release of $\mathrm{Ca}^{2+}$ from the Pro-BX steeply rose after the $100^{\text {th }}$ hour of sampling before levelling off. Overall, $\mathrm{Ca}^{2+}$ concentration of all the four biochar treatments fluctuated. The release of $\mathrm{Ca}^{2+}$ was highest for the Bioc treatment followed by the SVB, then the DWB and the
VTB (Figure 2(c)). The fluctuations in the concentrations of $\mathrm{Ca}^{2+}$ released into solution from the biochar treatments could be ascribed to ionic exchange activities on the carbonaceous surface of the biochar. Therefore, the present results can be explained by possible modification and activation of the biochar when it was inoculated with vermicast or deionized water followed by an incubation period as reported by Sizmur et al. [18]. From Figures 2(a)-2(d), it seemed the concentrations of $\mathrm{NO}^{3-}, \mathrm{K}^{+}, \mathrm{Ca}^{2+}$, and $\mathrm{Na}^{+}$from each of the biochar treatments will continue to rise if the sampling time was extended beyond the $591 \mathrm{hr}$ of the nutrient release study. The variation in the trend of nutrient release from the different media treatments is an indication of possible variations in nutrient availability for plant uptake and utilization for growth and development.

Chlorophyll fluorescence activity was used to assess photosynthetic activities in Swiss chard cv. Rhubarb chard grown in different treatments. It was found that the 


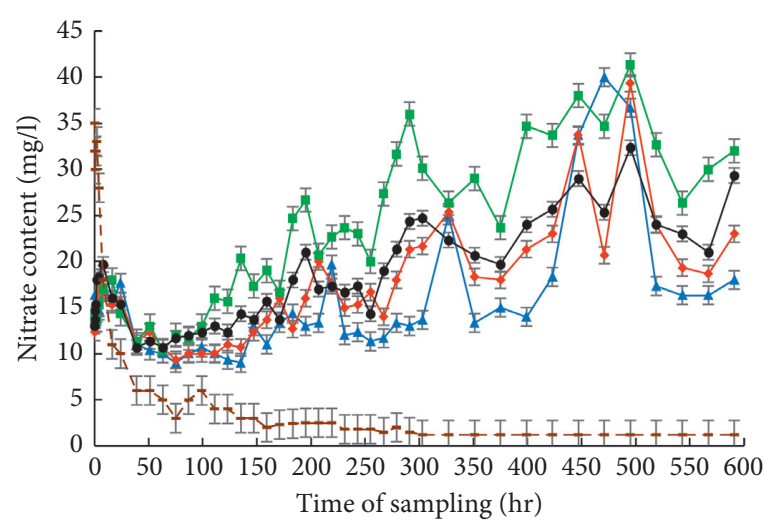

(a)

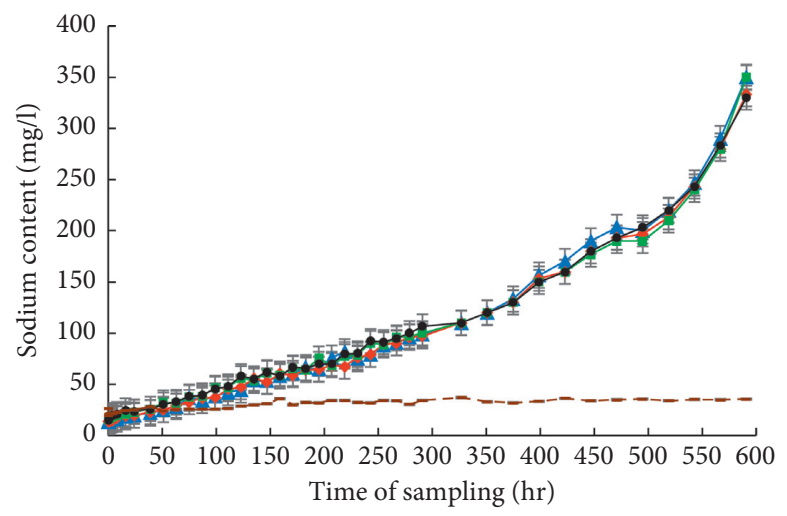

(c)

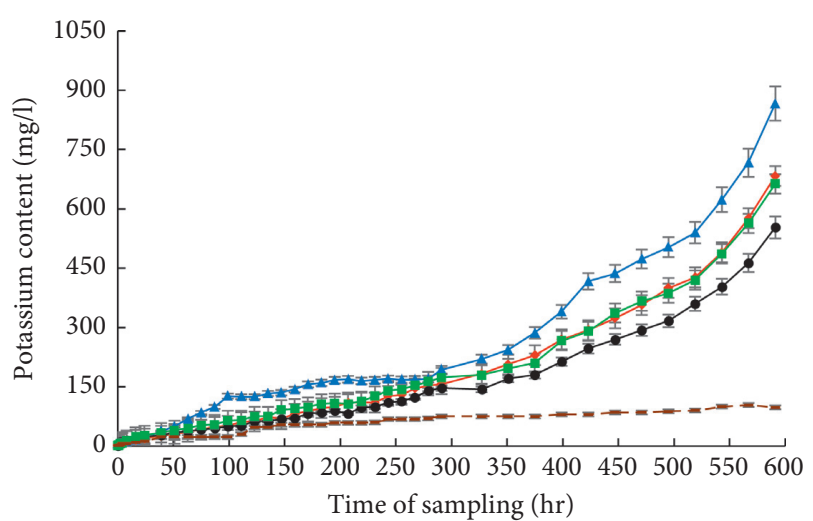

(b)

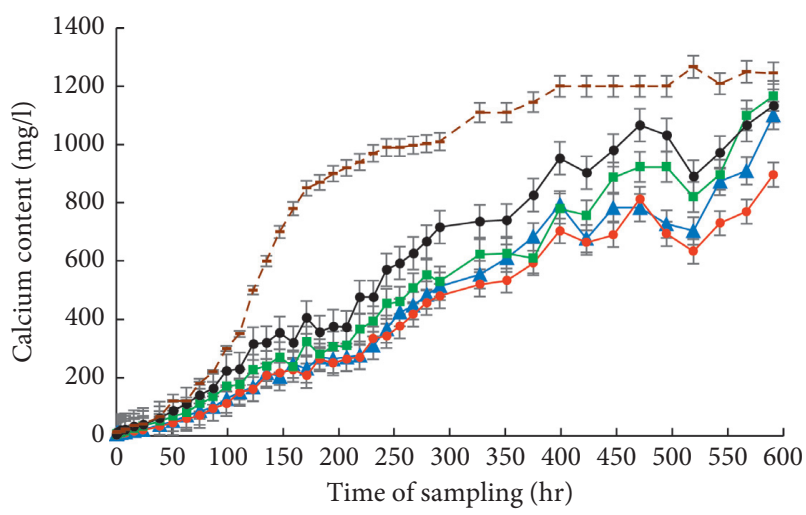

(d)

FIgURE 2: Release of potassium, sodium, nitrate, and calcium contents of solid vermicast-inoculated biochar (solid line, green square), vermicast tea-inoculated biochar (solid line, red rhombus), deionized water-inoculated biochar (solid line, blue triangle), biochar alone (solid line, black round), and Promix-BX alone (broken line, brown dash) in deionized water. Vertical lines represent standard error bars.

maximum quantum yields also termed as efficiency of photosystem II $(\mathrm{Fv} / \mathrm{Fm})$ for the Swiss chard plants ranged between 0.76 and 0.78 and were not significantly $(P>0.05)$ different between treatments (data not presented). Leaf chlorophyll content estimated using the SPAD value of leaf greenness was differentially influenced by the different medium treatments. Prior to the first harvest, i.e., four weeks after transplanting, the SPAD value was significantly highest in plants grown in the treatment Pro-BX followed by treatments SVB and VTB and lowest in treatments Bioc and DWB (Figure 3(a)).

However, there was a remarkable change in the extent to which the treatments affected the SPAD value of leaf greenness at the second harvest at eight weeks after transplanting. Treatments SVB and VTB equally increased SPAD value at the second harvest by $c a$. 0.44 -fold compared to the first harvest but was remarkably reduced in plants grown in the Pro-BX by ca. 0.38 -fold. It was noted that the change was, however, moderate in Swiss chard plants grown in the DWB and the Bioc. Leaf anthocyanin content was similar for all the plants irrespective of the medium treatment at the first harvest (Figure 3(b)). At the second harvest, only treatments VTB and SVB increased leaf anthocyanin contents by $c a$. 0.80 - and 0.95 -fold, respectively. These findings indicated that leaf pigmentation was significantly influenced by VTB and SVB compared to the other treatments. This further confirmed the slow release of nutrients from biochar inoculated with vermicast.

The number of Swiss chard green leaves and plant mass density, which indicate assimilate accumulation, were not significantly $(P>0.05)$ different among the treatments and between the two harvest times (data not presented). However, other plant growth components such as plant height, stem diameter, leaf fresh weight, and total leaf area were clearly affected (Figures 4(a)-4(d)). These plant growth components were significantly $(P<0.05)$ increased by treatment Pro-BX followed by treatments DWB and Bioc and the lowest by treatments SVB and VTB at the first harvest. But this growth trend changed at the second harvest.

Changes in plant height between the first and the second harvests were prominent for VTB and SVB. It was found that plant height increased by approximately 2.03 -fold for VTB and by 0.67 -fold for SVB and did not significantly $(P>0.05)$ change for Bioc or DWB, but significantly $(P<0.05)$ reduced by ca. 0.45 -fold for Pro-BX. Swiss chard plant stem diameter was increased by approximately 1.66-fold for VTB and 0.59fold for SVB while minor nonsignificant changes were recorded for Bioc and DWB. The Pro-BX, on the other hand, significantly $(P<0.05)$ reduced stem diameter by $c a .0 .47-$ fold at the second harvest. The trend for both total leaf 


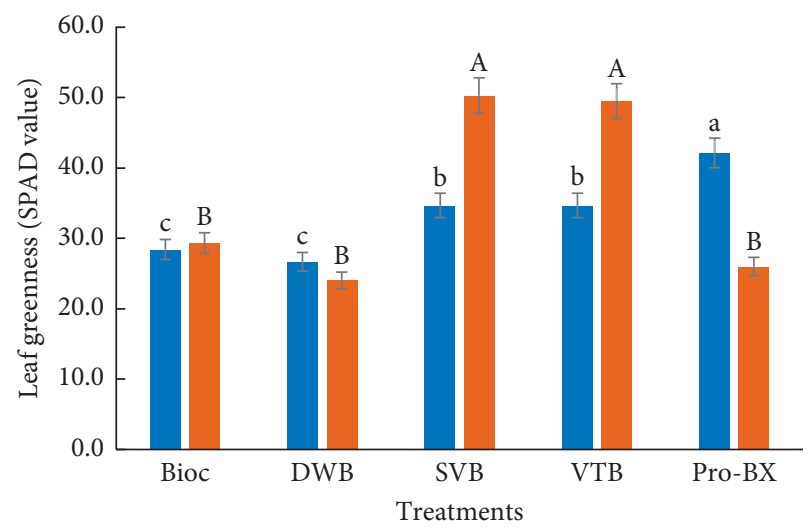

- LG1

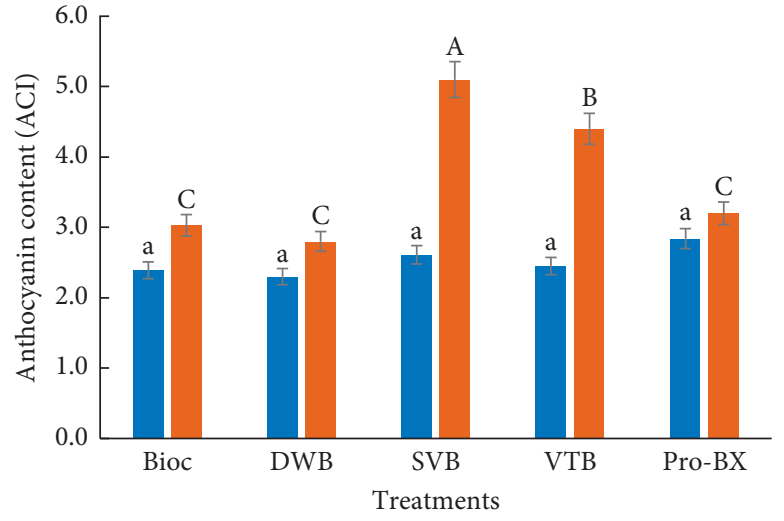

- $\mathrm{AC} 1$

- AC2

(a)

(b)

FIGURE 3: Leaf greenness and anthocyanin content of Swiss chard (Beta vulgaris subsp. vulgaris) cv. Rhubarb chard as affected by biochar alone (Bioc), deionized water-inoculated biochar (DWB), solid vermicast-inoculated biochar (SVB), vermicast tea-inoculated biochar (VTB), and Promix-BX alone (Pro-BX). Lowercase and uppercase alphabetical letters represent mean separation by the least significant difference $(\alpha=0.05)$ at the first (1) and the second (2) harvests, respectively. Vertical lines on bars represent standard error of the means.
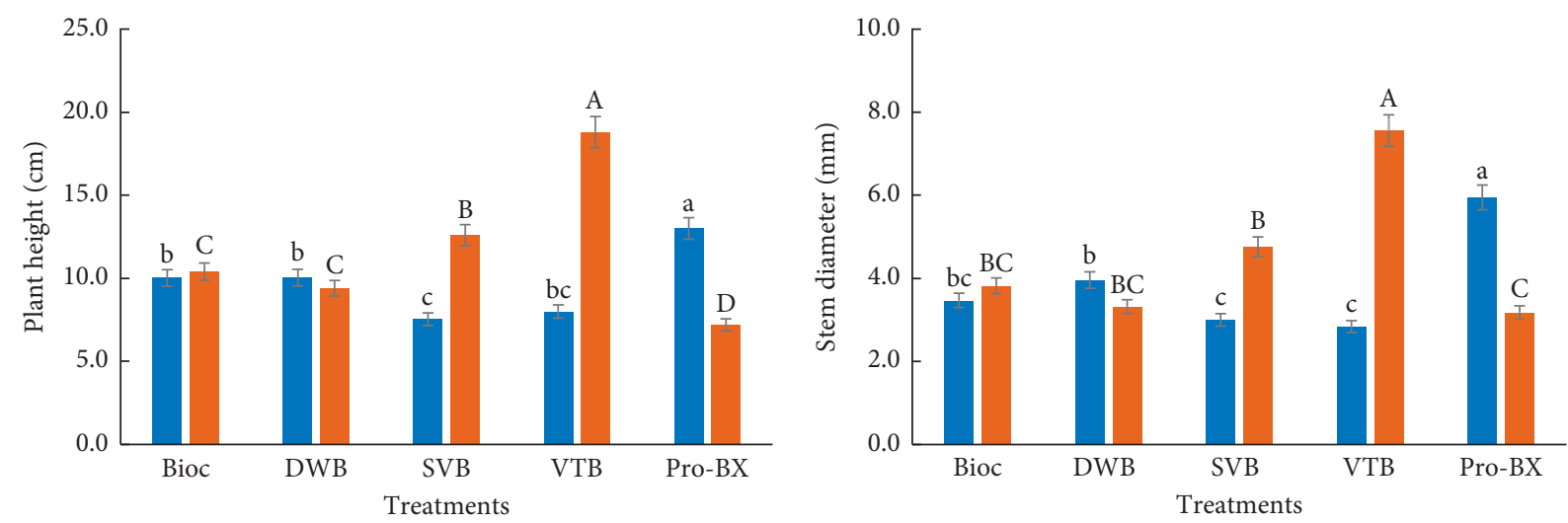

$$
\begin{aligned}
& \text { PH1 } \\
& \text { PH2 }
\end{aligned}
$$

$$
\begin{array}{r}
\text { SD1 } \\
\text { SD2 }
\end{array}
$$

(a)
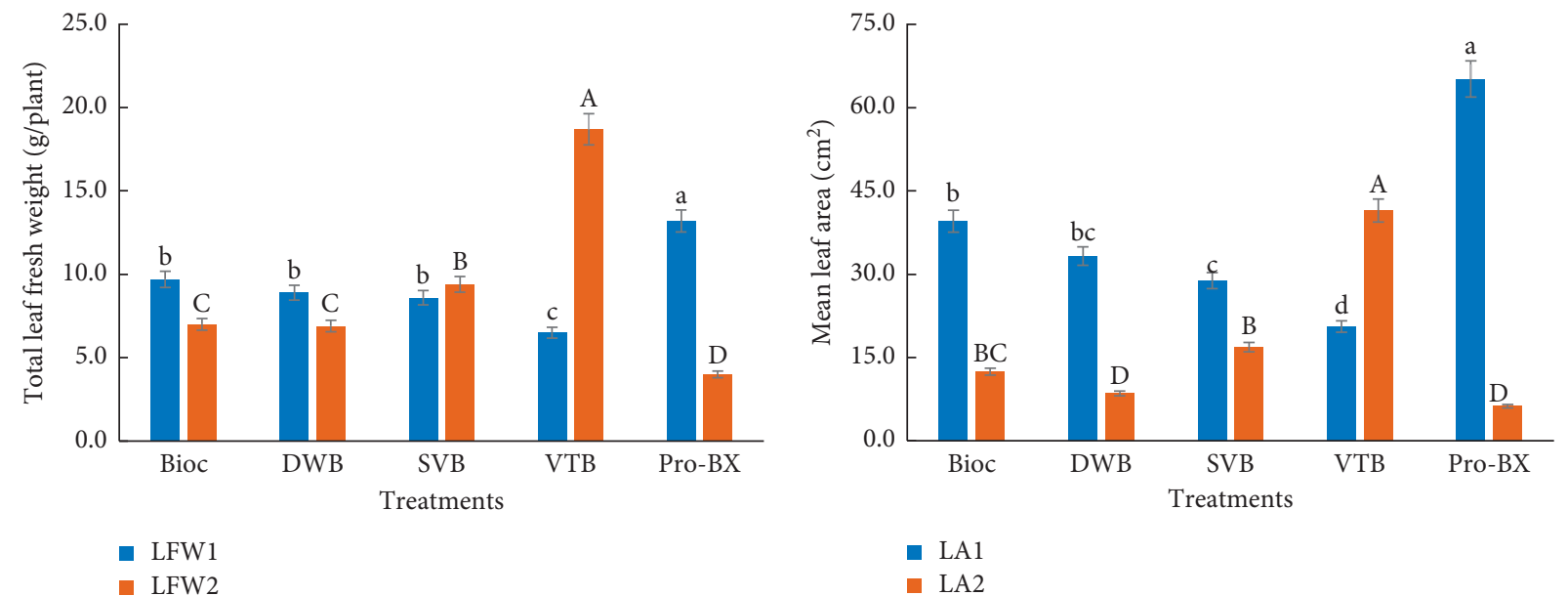

LFW2

LA2

(c)

(d)

Figure 4: Plant height (PH), stem diameter (SD), leaf area (LA), and total edible leaf fresh weight (LFW) of Swiss chard (Beta vulgaris subsp. vulgaris) cv. Rhubarb chard as affected by biochar alone (Bioc), deionized water-inoculated biochar (DWB), solid vermicast-inoculated biochar (SVB), vermicast tea-inoculated biochar (VTB), and Promix-BX alone (Pro-BX). Lowercase and uppercase alphabetical letters represent mean separation by the least significant difference $(\alpha=0.05)$ at the first $(1)$ and the second $(2)$ harvests, respectively. Vertical lines on bars represent standard error of the means. 
surface area and fresh weight at first harvest was Pro$\mathrm{BX}>\mathrm{Bioc}>\mathrm{DWB}=\mathrm{SVB}>\mathrm{VTB}$ (Figures 4(c) $-4(\mathrm{~d})$ ). This trend drastically changed at the second harvest. The only treatment that increased total leaf area and leaf fresh weight at the second harvest was VTB, i.e., by approximately 1.02and 1.88 -fold compared to those at the first harvest. On the contrary, total leaf area was significantly $(P<0.05)$ reduced by approximately 0.42 -fold for SVB, 0.74 -fold for DWB, 0.69-fold for Bioc, and 0.90-fold for Pro-BX (Figure 4(c)), while leaf fresh weight was significantly reduced by approximately 0.33 -fold for DWB, 0.28 -fold for Bioc, and 0.70fold for Pro-BX but was not altered by SVB (Figure 4(d)) at the second harvest as compared to the first harvest. A 2dimensional biplot principal component analysis (PCA) was used to further explain relationships between the treatments and the growth components. The PCA biplot explained 92\% of the variations in the dataset for the plant growth components as affected by the media treatments Pro-BX, Bioc, DWB, SVB, and VTB (Figure 5).

There were distinct differences in the media except that Bioc and DWB were similar and both appeared in the same quadrant on the PCA biplot. The plant growth components at the first harvest can be found in the first quadrant with the Pro-BX treatment. This suggested that the PCA plot agreed with Figures 3 and 4 that the Pro-BX treatment significantly increased plant growth components at the first harvest. Both SVB and VTB can be found in quadrant 2 of the PCA biplot with the plant growth components at the second harvest. The location of SVB relative to VTB and the plant growth components suggested that the latter was more effective in influencing the plant growth components. Neither Bioc nor DWB influenced plant growth. These showed that the effect of treatment VTB, which was not apparent in the first four weeks, became obvious. Additionally, VTB recorded the highest effect on the Swiss chard plant growth components at the second harvest. Thus, the VTB treatment delayed the release of nutrients but was made available eventually to increase the Swiss chard plant growth and yield during the regrowth phase after the first harvest. These findings can be confirmed by the results of the nutrient release experiments in Figures 1 and 2 as shown on the PCA biplot.

In conclusion, the study confirmed that inoculation of biochar with vermicast can increase its adsorption capacity for nutrients, which will subsequently be released slowly to plants for root uptake and plant utilization. It is evident from the present study that the nutrient release rate of inoculated biochar is initially slow. Vermicast tea-inoculated biochar and solid vermicast-inoculated biochar have similar nutrient release patterns and proved to be highly activated. Inoculated biochar characteristically releases nutrients slowly with a long-lasting impact on growing media, environment, and ultimately, plant productivity. Comparatively, vermicast tea was the most effective in inoculation of the biochar, and as such, it was the most efficacious under the conditions of this study. Future investigation should consider microbial activities in these media.

DWB, deionized water-inoculated biochar; SVB, solid vermicast-inoculated biochar; VTB, vermicast tea-inoculated biochar; Pro-BX, Promix-BX.

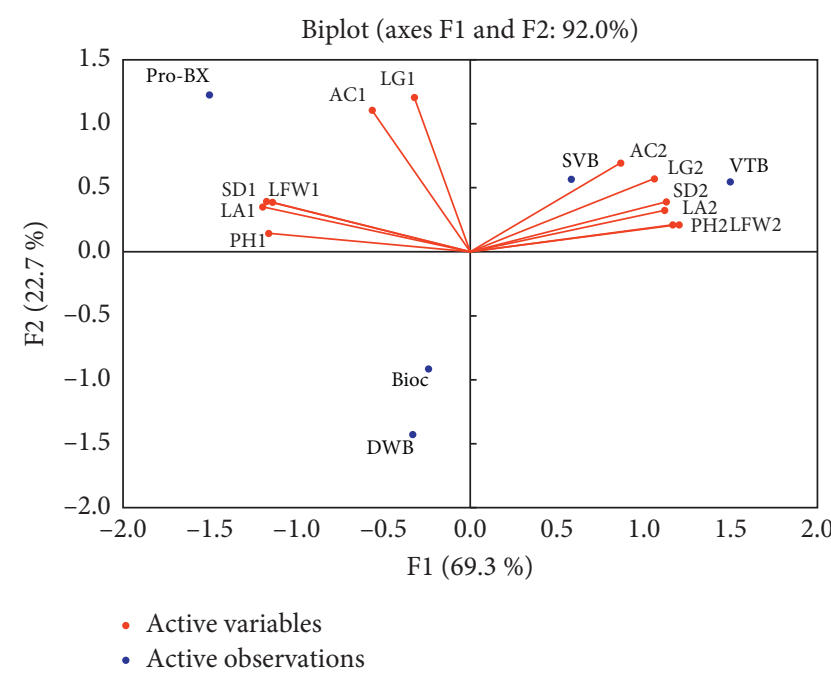

FIgURE 5: A two-dimensional principal component analysis biplot showing relationships among media treatments as active variables and plant growth components as active observations. Plant growth components were leaf greenness (LG), anthocyanin content (AC), plant height $(\mathrm{PH})$, stem diameter (SD), leaf area (LA), and total edible leaf fresh weight (LFW) of Swiss chard (Beta vulgaris subsp. vulgaris) cv. Rhubarb chard as affected by biochar alone (Bioc), deionized water-inoculated biochar (DWB), solid vermicast-inoculated biochar (SVB), vermicast tea-inoculated biochar (VTB), and Promix-BX alone (Pro-BX) at the first (1) and the second (2) harvests, respectively.

\section{Data Availability}

The nutrient release, plant nutrient uptake, and plant growth data used to support the findings of this study are included within the supplementary information files.

\section{Conflicts of Interest}

The authors declare that they have no conflicts of interest.

\section{Acknowledgments}

The authors wish to thank Dr. Samuel Asiedu for his assistance during the experimentation and Dr. Nancy MacLean for her guidance on performing the statistical analysis. However, the authors wish to thank Proton Power Inc., Tennessee, USA, for the donation of the biochar.

\section{Supplementary Materials}

The supplementary files with data showed in S1-S11 were used to report the outcomes of the study. The common acronyms used were as follows: Bioc=biochar alone; $\mathrm{DWB}=$ deionized water-inoculated biochar; $\mathrm{SVB}=$ solid vermicast-inoculated biochar; $\mathrm{VTB}=$ vermicast tea-inoculated biochar; Pro-BX = Promix-BX soilless medium alone. S1: the data for the various growing medium salinity content during the nutrient release studies. S2: the data for the changes in electric conductivity of the solution when the individual media were submerged in deionized water. S3: the changes in the acidity level (i.e., $\mathrm{pH}$ ) of the solution when the 
individual media were submerged in deionized water. S4: the total dissolved solids in solution when the individual media were submerged in deionized water. S5, S6, S7, and S8: the concentrations of calcium, potassium, nitrate, and sodium ions in solution when the individual media were submerged in the deionized water. S9: the data for a two-dimensional principal component analysis biplot showing relationships among media treatments as active variables and plant growth components as active observations. Plant growth components were leaf greenness (LG), anthocyanin content (AC), plant height (PH), stem diameter (SD), leaf area (LA), and total edible leaf fresh weight (LFW) of Swiss chard (Beta vulgaris subsp. vulgaris) $\mathrm{cv}$. Rhubarb chard as affected by the growing medium treatments at the first (1) and the second (2) harvests, respectively. S10: the data for the mineral nutrient composition of the individual growing media before the beginning of the nutrient release studies. S11: the data for plant growth and yield components as affected by the individual growing medium treatments. (Supplementary Materials)

\section{References}

[1] G. Agegnehu, A. K. Srivastava, and M. I. Bird, "The role of biochar and biochar-compost in improving soil quality and crop performance: a review," Applied Soil Ecology, vol. 119, pp. 156-170, 2017.

[2] R. Xiao, M. K. Awasthi, R. Li et al., "Recent developments in biochar utilization as an additive in organic solid waste composting: a review," Bioresource Technology, vol. 246, pp. 203-213, 2017.

[3] Y. Yuan, H. Chen, W. Yuan, D. Williams, J. T. Walker, and W. Shi, "Is biochar-manure co-compost a better solution for soil health improvement and $\mathrm{N} 2 \mathrm{O}$ emissions mitigation?" Soil Biology and Biochemistry, vol. 113, pp. 14-25, 2017.

[4] A. Grewal, L. Abbey, and L. R. Gunupuru, "Production, prospects and potential application of pyroligneous acid in agriculture," Journal of Analytical and Applied Pyrolysis, vol. 135, pp. 152-159, 2018.

[5] G. Agegnehu, A. M. Bass, P. N. Nelson, B. Muirhead, G. Wright, and M. I. Bird, "Biochar and biochar-compost as soil amendments: effects on peanut yield, soil properties and greenhouse gas emissions in tropical North Queensland, Australia," Agriculture, Ecosystems \& Environment, vol. 213, pp. 72-85, 2015.

[6] N. Khan, I. Clark, M. A. Sanchez-Monedero et al., "Physical and chemical properties of biochars co-composted with biowastes and incubated with a chicken litter compost," Chemosphere, vol. 142, pp. 14-23, 2016.

[7] F. Rees, C. Germain, T. Sterckeman, and J.-L. Morel, "Plant growth and metal uptake by a non-hyperaccumulating species (Lolium perenne) and a Cd-Zn hyperaccumulator (Noccaea caerulescens) in contaminated soils amended with biochar," Plant and Soil, vol. 395, no. 1-2, pp. 57-73, 2015.

[8] J. Pietikainen, O. Kiikkila, and H. Fritze, "Charcoal as a habitat for microbes and its effect on the microbial community of the underlying humus," Oikos, vol. 89, no. 2, pp. 231-242, 2000.

[9] L. Beesley, E. Moreno-Jiménez, and J. L. Gomez-Eyles, "Effects of biochar and greenwaste compost amendments on mobility, bioavailability and toxicity of inorganic and organic contaminants in a multi-element polluted soil," Environmental Pollution, vol. 158, no. 6, pp. 2282-2287, 2010.
[10] N. Hagemann, K. Spokas, H.-P. Schmidt, R. Kägi, M. Böhler, and T. Bucheli, "Activated carbon, biochar and charcoal: linkages and synergies across pyrogenic carbon's ABCs," Water, vol. 10, no. 2, pp. 182-201, 2018.

[11] C. Sreenivas, S. Muralidhar, and M. S. Rao, "Vermicompost: a viable component of IPNSS in nitrogen nutrition of ridge gourd," Annals of Agricultural Research, vol. 21, no. 1, pp. 108-113, 2000.

[12] AOAC, Protein (Crude) in Animal Feed: Combustion Method, AOAC Official Method 990.03. Official Methods of Analysis, Association of Official Analytical Chemists, Gaithersburg, MD, USA, 17th edition, 2003.

[13] AOAC, Metals and Other Elements in Plants and Pet Foods: Inductively Coupled Plasma Spectroscopic Method, AOAC Official Method 968.08. Official Methods of Analysis, Association of Official Analytical Chemists, Gaithersburg, MD, USA, 17th edition, 2003.

[14] L. Abbey, S. A. Rao, L. N. Hodgins, and F. Briet, "Drying and rehydration of vermicasts do not affect nutrient bioavailability and seedling growth," American Journal of Plant Nutrition and Fertilization Technology, vol. 3, no. 1, pp. 12-21, 2013.

[15] A. E. Louw-Gaume, I. M. Rao, A. J. Gaume, and E. Frossard, "A comparative study on plant growth and root plasticity responses of two Brachiaria forage grasses grown in nutrient solution at low and high phosphorus supply," Plant and Soil, vol. 328, no. 1-2, pp. 155-164, 2010.

[16] K. Maxwell and G. N. Johnson, "Chlorophyll fluorescence-a practical guide," Journal of Experimental Botany, vol. 51, no. 345 , pp. 659-668, 2000.

[17] H. Wu, C. Lai, G. Zeng et al., "The interactions of composting and biochar and their implications for soil amendment and pollution remediation: a review," Critical Reviews in Biotechnology, vol. 37, no. 6, pp. 754-764, 2016.

[18] T. Sizmur, T. Fresno, G. Akgül, H. Frost, and E. MorenoJiménez, "Biochar modification to enhance sorption of inorganics from water," Bioresource Technology, vol. 246, pp. 34-47, 2017.

[19] L. Martínez-Suller, G. Provolo, D. Brennan et al., "A note on the estimation of nutrient value of cattle slurry using easily determined physical and chemical parameters," Irish Journal of Agricultural and Food Resarch, vol. 49, pp. 93-97, 2010. 